Low bone mass in young patient with Crohn disease:

\title{
to treat or not to treat?
}

Iulia Soare ${ }^{2}$, Anca Sirbu ${ }^{1,2}$, Cristian Tieranu ${ }^{1,2,}$, Mirela lonescu, ${ }^{1,2}$, Simona Fica ${ }^{1,2}$

${ }^{1}$ Elias Emergency Hospital, Endocrinology Department, Bucharest, Romania

${ }^{2}$ Carol Davila University of Medicine and Pharmacology, Endocrinology Department, Bucharest, Romania

Decreased bone mass is associated with inflammatory bowel disease (IBD), due to multiple factors, including endocrine disturbances, deficits in calcium and vitamin $D$, malnutrition, drugs (corticosteroids), chronic inflammation. If in older man and postmenopausal women, the treatment is well established, for young patients is not a general consensus.

\section{CASE REPORT}

We report the case of a 20-year-old, male, nonsmoker, diagnosed with Crohn disease (2010), complicated with axial spondylarthrosis. He received glucocorticoids high dose at least 2 times (>3 months). Between 2011-2017, he was lost of the follow up, as his parents decided to use non-pharmacological treatments. In 2017, he was admitted to hospital with abdominal abscess, severe denutrition ( $\mathrm{BMI}=12,3 \mathrm{~kg} / \mathrm{m} 2$ ), impaired weight bearing, limited range of motion of bilateral hip joints. His blood tests showed inflammation, feriprive anemia, hypoalbuminemia. We performed DXA, who showed L1-L4: BMD 0,806 g/cm2, Z score=-3.5 DS, left hip: BMD $0.775 \mathrm{~g} / \mathrm{cm} 2$, Z score=-3. 4 DS, BMD (TBLH) =-3. 6 DS, TBS score L1-L4=1,031. His hormonal tests revealed deficit of vitamin $D$ ( 25 hidroxy vitamin $D=13,98$ $\mathrm{ng} / \mathrm{ml}$ ), low testosterone and IGF1, normal thyroid function.

Gastroenterologist's decision was to initiate Infliximab, after parenteral nutrition, antibiotic and drainage of the abscess. The challenge was whether to initiate the anti-osteoporotic treatment or not. As the disease was not well controlled, correlated with deficit in vitamin $D$, we decided first to administer cholecalciferol (4000 UI/day, for 6 weeks) and then reconsider bisphosphonates. As after 6 weeks, his level of 25 hidroxi vitamin D was still low (15 ng/ml) despite daily administration, we decided to give cholecalciferol 100000 i.m; follow-up is needed.

\section{Segment \\ Bone mass density \\ Z score}
L1-L4
$0,806 \mathrm{~g} / \mathrm{cm} 2$
$-3,5$ DS
Left hip
$0.775 \mathrm{~g} / \mathrm{cm} 2$
$-3,4$ DS

\section{CONCLUSION:}

Low bone density in young adults is an important complication for patients with chronic diseases, so every case is treated individualized.

\section{REFERENCES:}

Inflammatory Bowel Disease: Effects on Bone and Mechanisms, Sylvester FA, Adv Exp Med Biol. 2017;1033:133-150. doi: 10.1007/978-3-319-66653-2_7 ${ }^{1}$ 